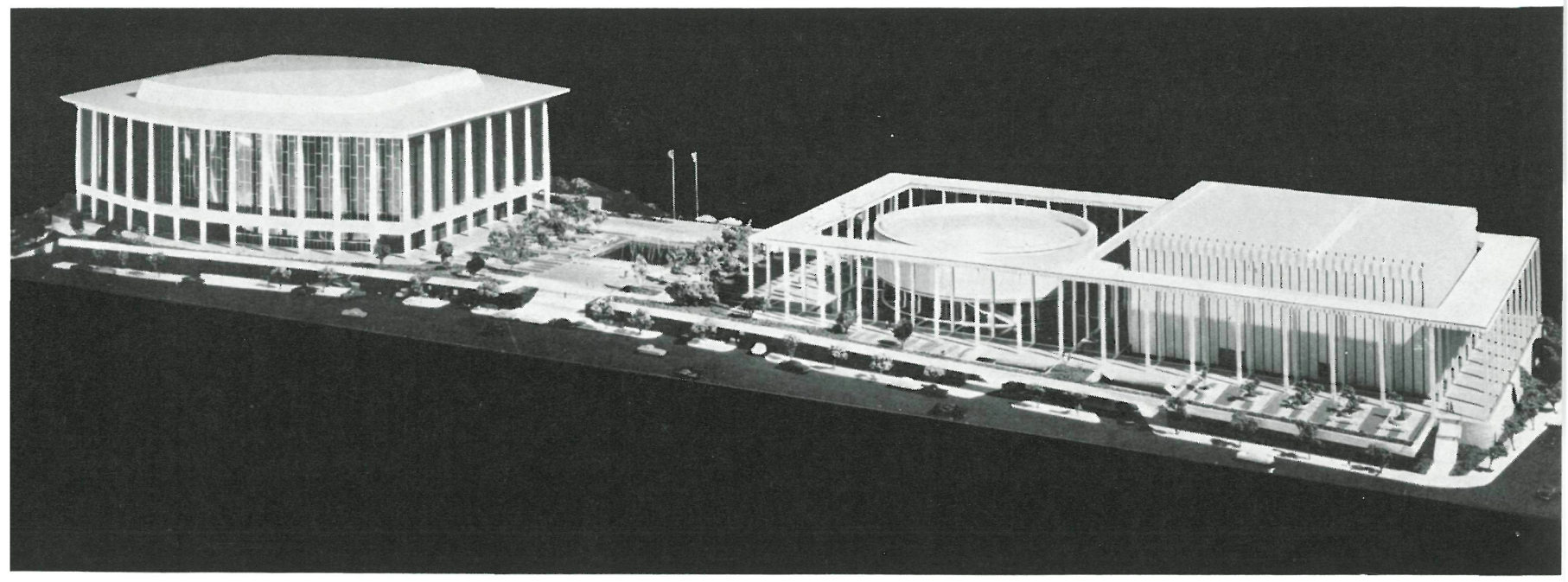

$146 \cdot 71$

\title{
Centrom masical
} en Los Angeles - U.S.A.

WELTON BECKET y ASOCIADOS, simopisis

El auditorio de este gran complejo artístico tiene una capacidad para 3.250 butacas, $\mathbf{y}$ está destinado a servir para múltiples usos, tales como: teatro de ópera; sala de conciertos; representaciones de ballet; etc.

El concepto arquitectónico seguido por los arquitectos, en el exterior, fue el de imprimirle una expresión contemporánea partiendo de un tema clásico; $y$ en el interior, el detalle de una elegancia adecuada, a tono de las manifestaciones que en él se celebran.

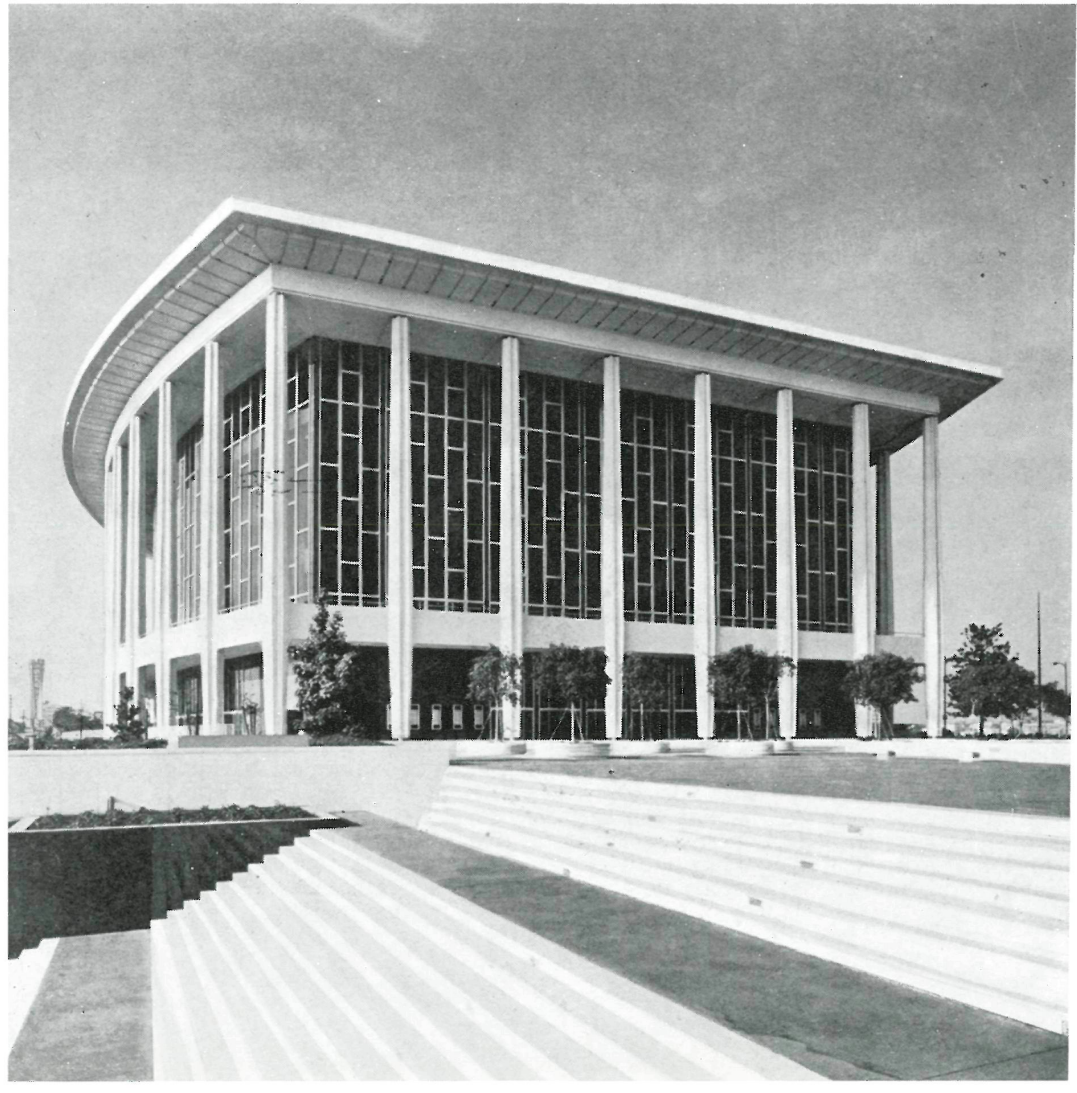

Lindando con el Centro Cívico de Los Angeles, entre las calles Temple, Hope Sts. y la Gran Avenida, ha sido proyectado un Centro para la celebración de representaciones artísticas, que una vez terminado constará de tres edificios: el "Center Theatern, un auditorio con 2.100 localidades, donde se representarán obras teatrales; el «Mark Taper Forum», un teatro circular con 750 asientos, destinado para obras experimentales y recitales; y el "Pavilion», una sala con 3.250 butacas que sirve para: teatro de ópera; sala de conciertos; representaciones de ballet; recitales; etc.

El auditorio del "Pavilion" -que es la primera unidad terminada del ambicioso Centro-, además de su extraordinaria capacidad, ofrece una gran flexibilidad y en él se desarrollan las actividades de diferentes Entidades: la Asociación Sinfónica de California, la Compañia de Opera de San Francisco, etc.; celebrándose, asimismo, relevantes representaciones de otro tipo, a gran escala.

El edificio mide $100,58 \mathrm{~m}$ de longitud $\mathrm{y}$ $76,81 \mathrm{~m}$ de anchura. El concepto arquitectónico que persiguieron los arquitectos al proyectarlo, fue el de conseguir una expresión contemporánea de un tema clásico arquitectónico.

En cuanto al interior del auditorio, todas las zonas de butacas fueron cuidadosamente diseñadas para que gozase el público te óptimas condiciones acústicas; y se las de ótimas condiciones acústicas, y se las dotó del sentido de elegancia preciso, con una sensación de intimidad y superación, una sensacion de intimidad y superación, las representaciones. 


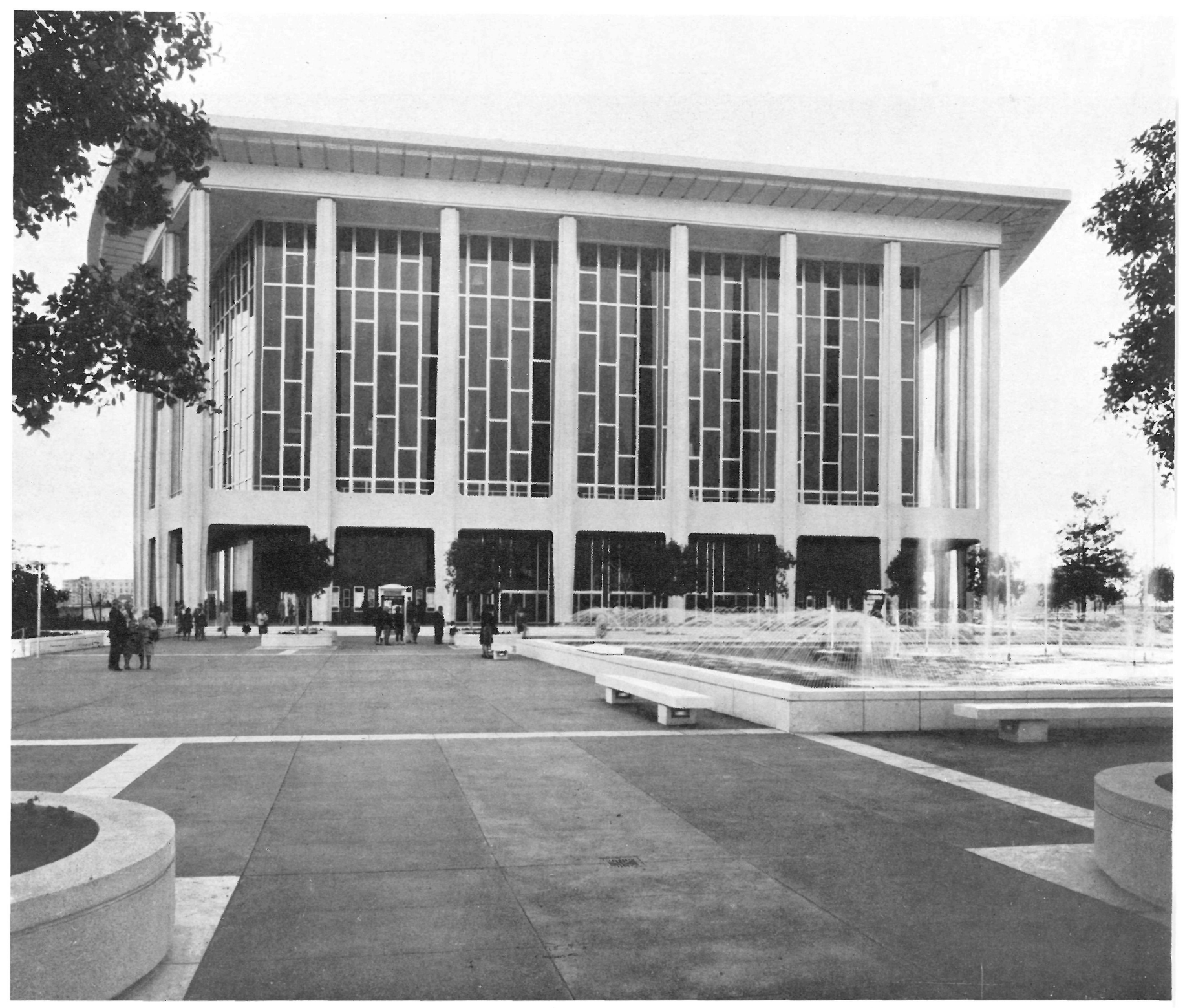

Aunque el escenario es muy bajo -en relación con los standards americanos usales-, el ángulo de visión del espectador nunca es inferior a $27^{\circ}$ y cada asiento disfruta de una visión clara del centro de la embocadura del escenario.

El patio de butacas es sensiblemente cuadrado y tiene 1.472 butacas, distribuidas en 27 filas. Dicha distribución y la de pasillos son tales que permiten desalojar completamente la sala en un tiempo máximo de minuto a minuto y medio lo que supone una considerable ventaja, en los intermedios, así como para facilitar la salida en un caso de emergencia.

El primer nivel -el del anfiteatro «Founders Circle»- tiene 467 localidades, que han sido diseñadas con gran elegancia y comodidad; las restantes butacas están repartidas entre los pisos primero, segundo y tercero.

Es digno de mencionar el escenario del «Pavilion», ya que en él están aplicados los más avanzados conceptos del diseño escénico, y por ser quizás el más grande y flexible escenario que hay actualmente en U.S.A.

Proyectado pensando en que sirviese para todos los diferentes tipos de representaciones artísticas que en él iban a tener lugar, posee las dimensiones y dispositivos apropiados. La escena tiene 19,50 m de profundidad y $51,51 \mathrm{~m}$ de anchura, siendo posible y fácil el ampliarlo.

Son de destacar: el podio para la orquesta, que puede ser desmontado y almacenado; y asimismo la pantalla despiezada acústica, que vuela en la parte superior del proscenio hacia la sala y permite satisfacer las necesidades acústicas, variables en cada caso, según se trate de conciertos, ópera, etc. En la primera de sus posiciones, este techo acústico permite la radiación directa del sonido, que, partiendo de la orquesta, se reparte a todas las butacas de la sala, sin necesidad de recurrir al auxilio de medios electroacústicos; dicha posición es empleada en las sesiones de ópera y de concierto. La segunda posición requiere el refuerzo electroacústico de los altavoces, que ayudan a dirigir el sonido a cada una de las butacas de la sala. Una tercera posición, al moverse dicho techo, permite el empleo de los equipos extraordinarios destinados a iluminar el escenario y demás efectos especiales. 
CALLE HOPE

plantas

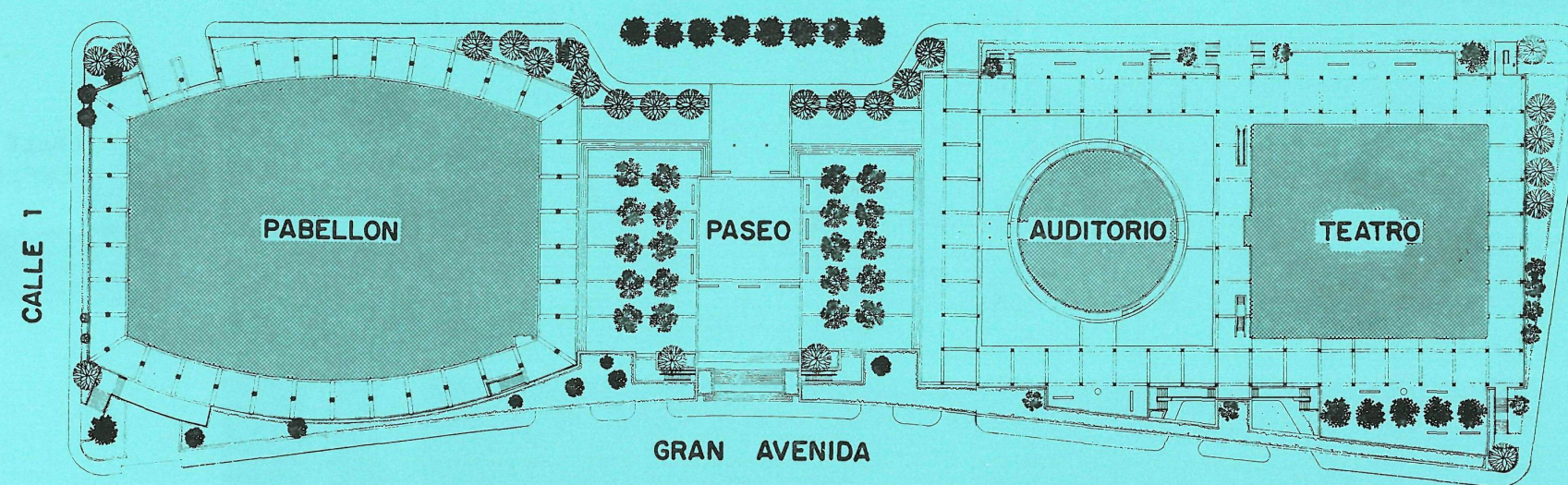

gemeral

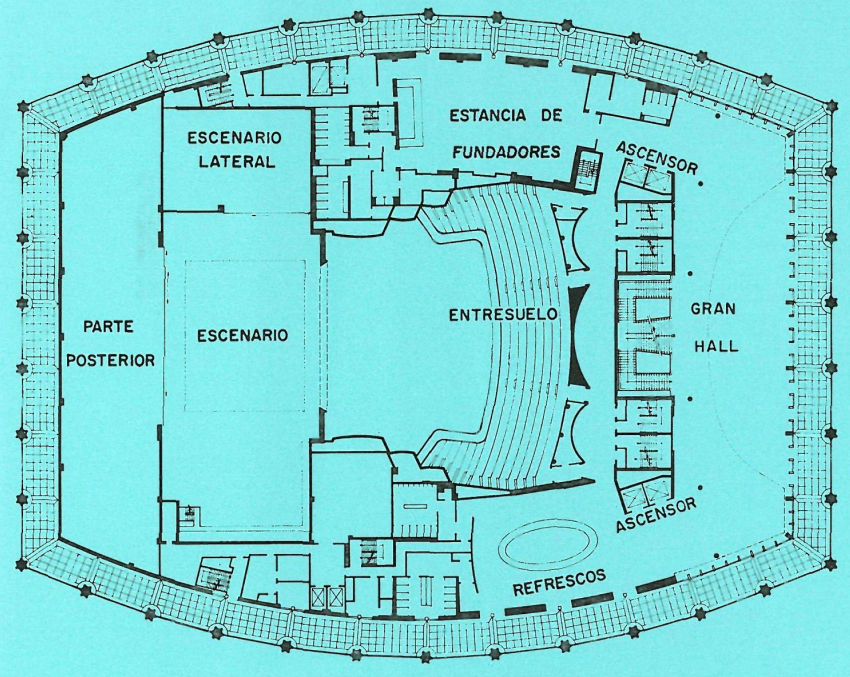

segunda

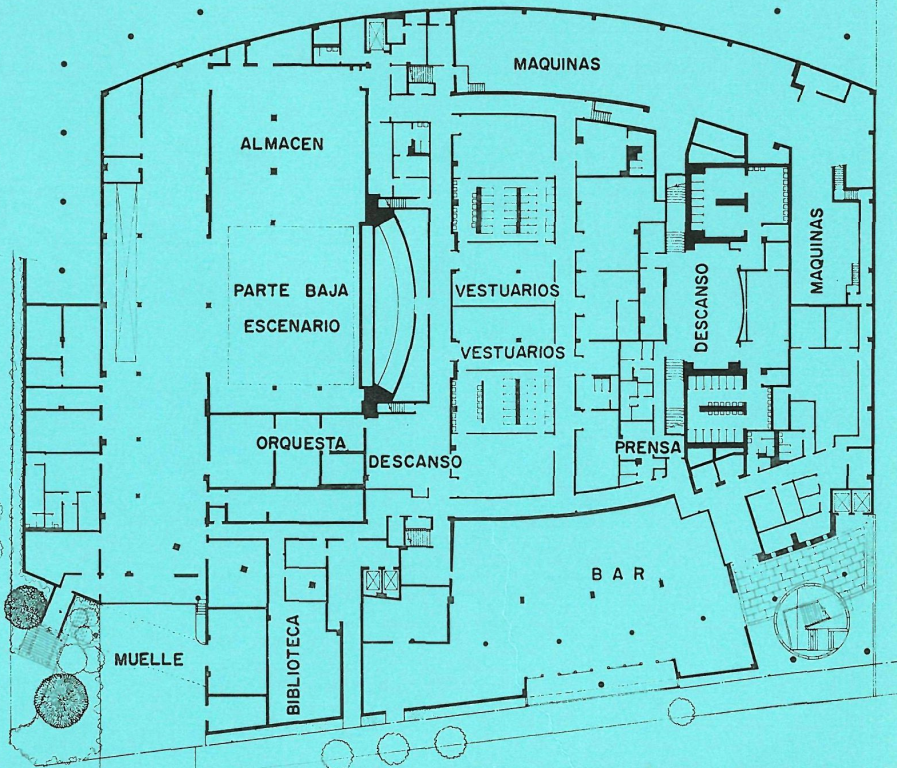

semiso์ที่

Al mismo nivel del escenario hay siete camerinos para estrellas, y los destinados para el director de la orquesta y solistas. En la entreplanta hay once camerinos más. Los camerinos para 100 componentes de ballet y 100 del coro, las salas de espera, y los vestuarios para los componentes masculinos y femeninos de la orquesta están debajo del escenario donde están situados también los almacenes de: vestuarios, de instrumentos, de decoraciones, etc. y una biblioteca musical.

El público entra a la gran sala desde la Plaza Mall a través de un gran vestíbulo, desde el cual arranca una impresionante escalera que asciende majestuosa a las cuatro plantas.

Todas las plantas disponen de su ambigú y de sus amplias zonas de descanso. Sobre el $3 .^{\circ}, 4 .^{\circ}$ y $5 .^{\circ}$ niveles existe un conjunto de oficinas - de las diferentes asociaciones de conciertos y musicales-, con sus respectivas salas de conferencias y de juntas. El $4 .^{\circ}$ piso contiene, además, cuatro grandes salas de ensayos, situadas sobre la parte posterior del de ensayos, situadas sobre la parte posterior del área de representación del escenario- y dos estudios de ensayos.

proinerea

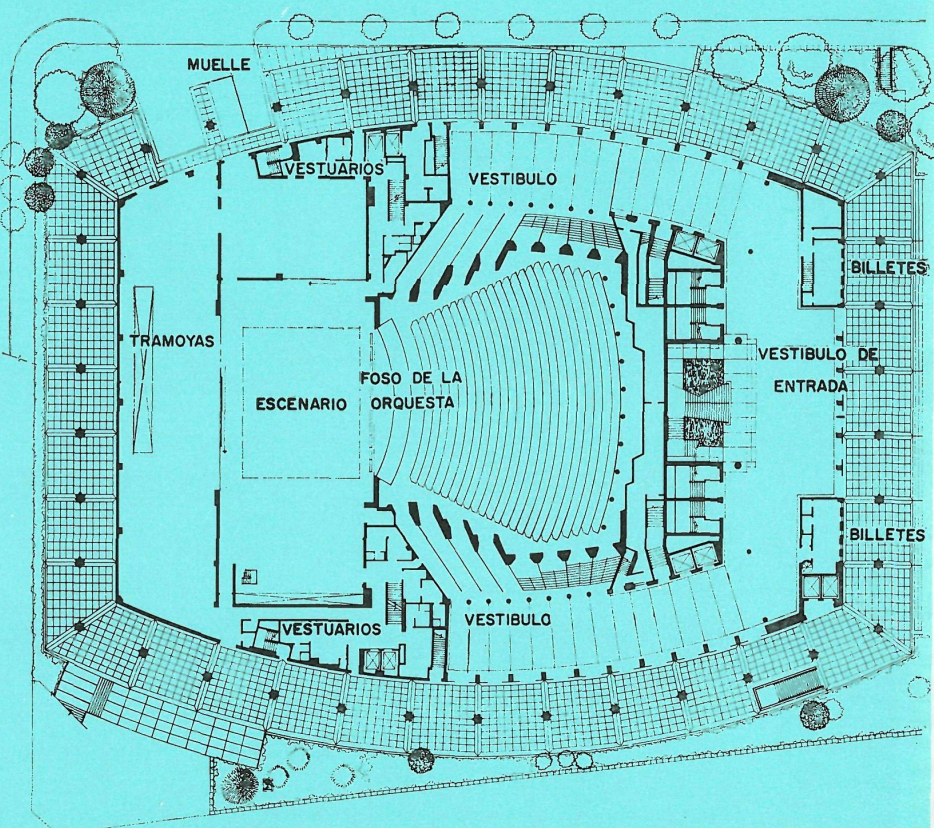




\section{SECEión}

PABELLON

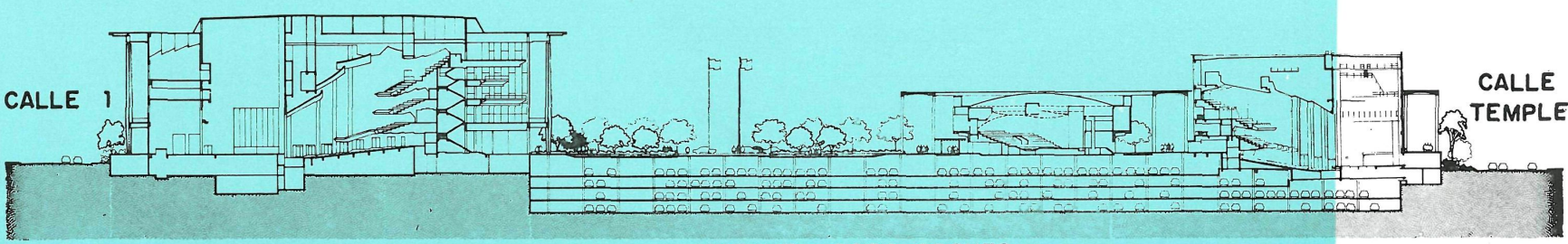

PASEO

AUDITORIO

TEATRO

GARAJE $=2000$ COCHES

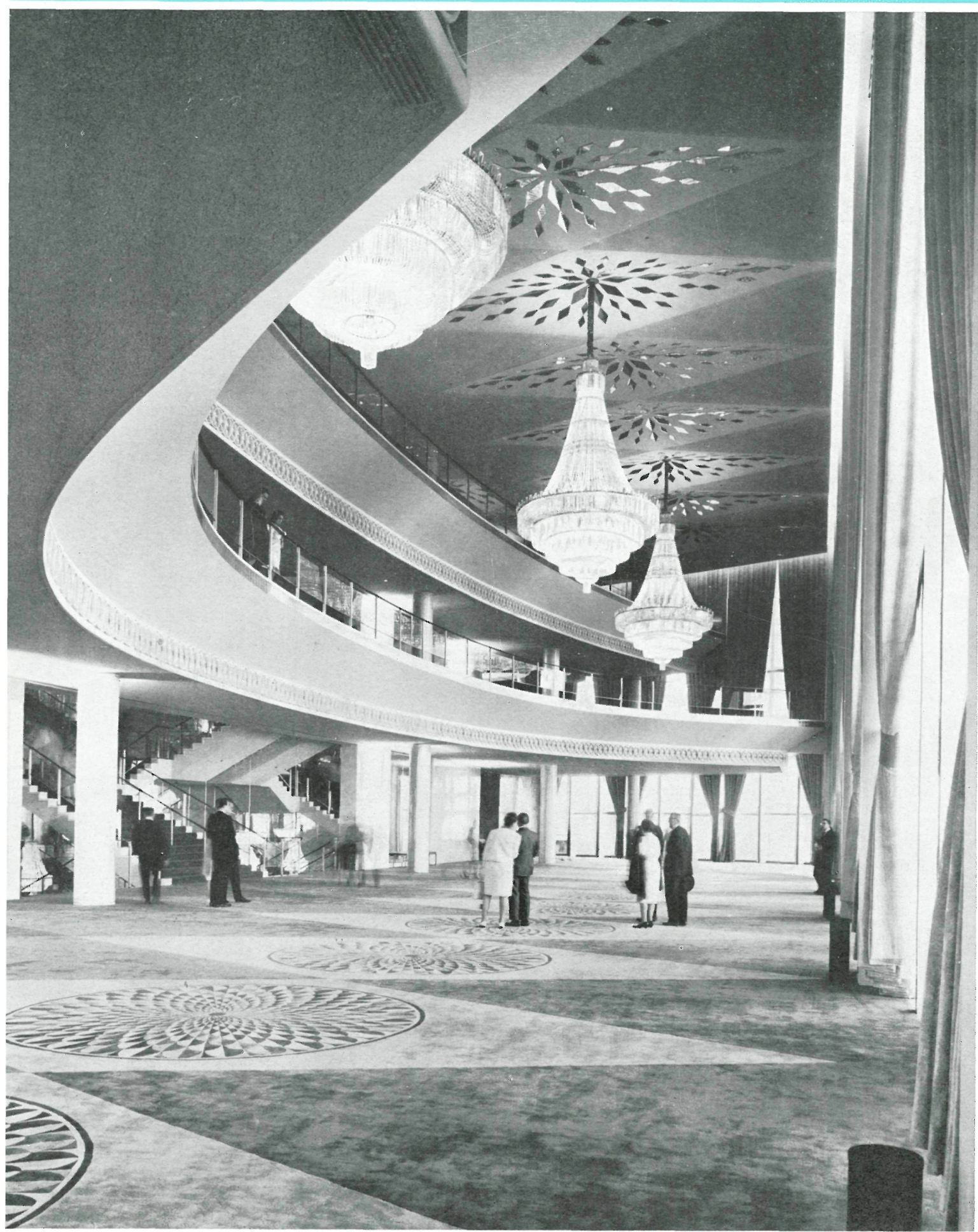



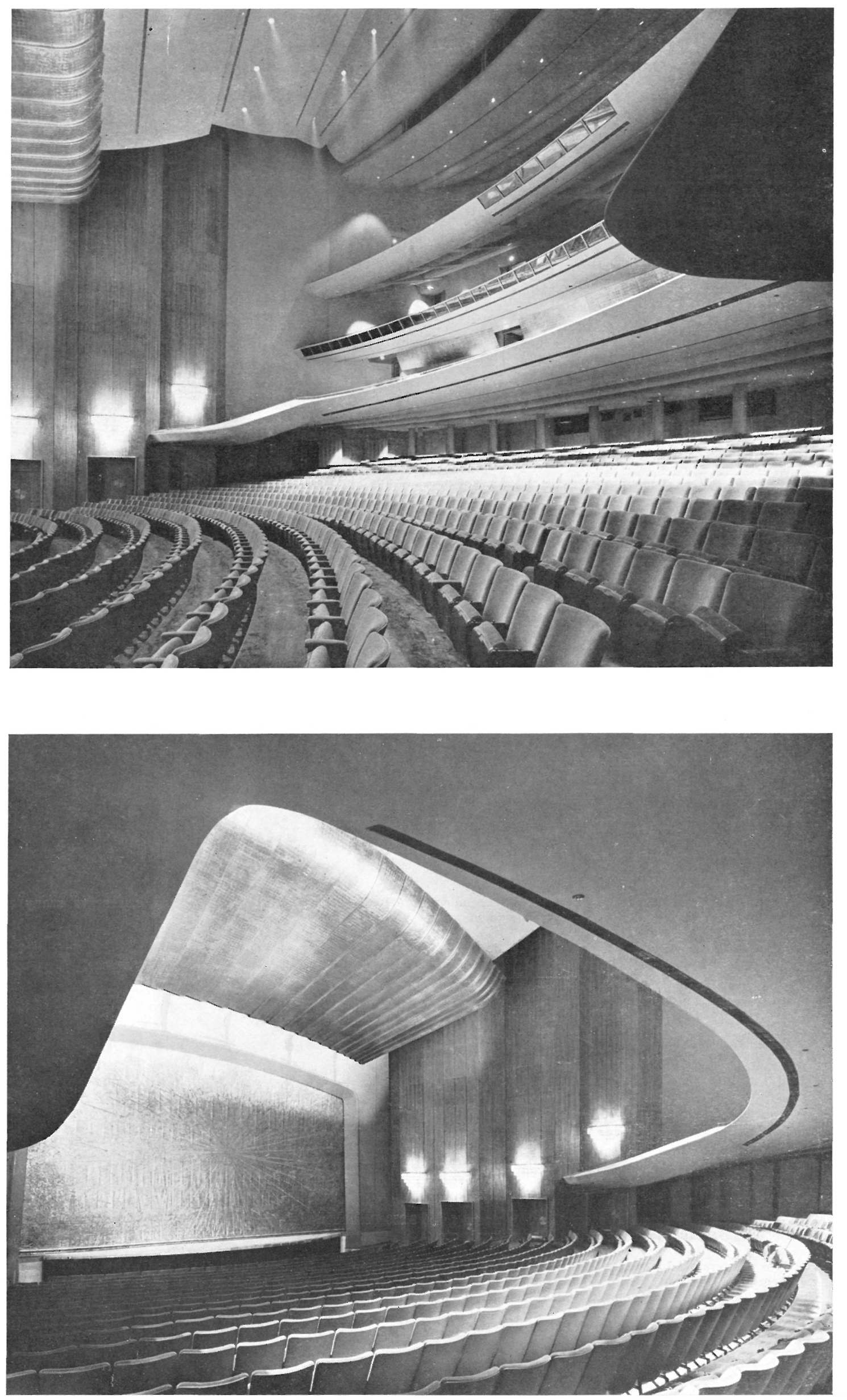
En la zona lateral del edificio, que linda con la Gran Avenida, y al nivel de la calle, se hallan: el restaurante "Curtain
Call", con capacidad para 130 comensales; una sala para cocktails adjunta, con 70 asientos, y cafetería, con 62 plazas sentados. Dicho restaurante está abierto al público, siendo particularmente cómodo para los asistentes al teatro, pues les permite comer antes o después de las representaciones.

Han sido asimismo dispuestas, en el edificio, las instalaciones para poder televisar las representaciones que se desee, existiendo un cuarto para el control principal, localizado en la parte posterior del nivel de la orquesta.

El diseño interior y decoración del «Pavilion» se distingue por su elegancia y belleza, y está especialmente adecuado para grandes manifestaciones culturales. Hay que destacar, en particular, el tratamiento dado al foyer de la entrada par destacar, en particular, el tratamiento dado al foyer de la entrada

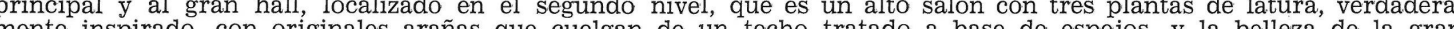
mala, en la que juegan un papel muy importante los contrastes de color establecidos.

Traducido y adaptado por J. M. Rubio.

\section{Cemtre mustical ì Los Angeles = Etats-Unis}

Welton Becket and Associates, architectes et ingénieurs.

Destiné à plusieurs usages, tels que théâtre d'opéra, salle de concerts, représentations de ballet, etc., l'auditorium de ce centre artistique comporte 3.250 stalles.

Le concept architectural suivi à l'extérieur par les architectes est de lui imprimer une expression contemporaine, partant d'un thème classique, et à l'intérieur, le détail d'une élégance en accord avec les manifestations qui s'y déroulent.

\section{Musical center ont Los Angeles - USA}

Welton Becket \& Associates, architects \& engineers.

The auditorium of this great artistic complex accommodates 3,250 seated spectators and can serve many uses, such as opera, concert, ballet and other performances.

The aim of the architects was to give the building a modern appearance externally, based on classical patterns, and inside, to care specially for detailed quality and elegance, in accord with its functional purpose.

\section{Mustikzentmum in Los Angeles = USA}

Welton Becket and Associates, Architekten und Ingenieure.

Der Zuschauerraum dieses grossen Kunstzentrum fasst 3.250 Personen und ist für vielfältige Zwecke geeignet, u.a. für Opern- und Ballettaufführungen, als Konzertsaal, etc.

Bei der Aussenansicht gingen die Architekten von einer klassischen Stilform aus, die sie mit modernen Stilmitteln zu verbinden bestrebt waren. Den Innenraum gestalteten sie in allen Einzelheiten mit grosser Eleganz, die dem Charakter der hier stattfindenden Aufführungen Rechnung trägt. 